\title{
Diabetes Mellitus and Tinnitus: an Epidemiology Study
}

Seyed Hasan Golboei MOUSAVI ${ }^{a}$, Batoolsadat SAJADINEJADa, Sina KHORSANDI ${ }^{b}$, Amin FARHADI ${ }^{\mathrm{C}}$

aDepartment of Otorhinolaryngology, School of Medicine, Birjand University of Medical Sciences, Iran

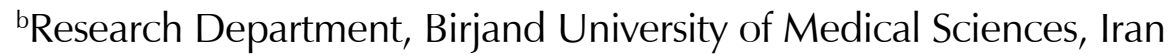

'Kavian Institute of Education, Mashhad, Iran

\begin{abstract}
- ABSTRACT
Objectives: Tinnitus is the perception of sound that does not arise from an external source. It is a chronic sensation that virtually all would prefer not to experience, but for most people it is not disabling and treatments for disturbing tinnitus are limited. Diabetes causes several side effects, among which its impact on the neural system is one of the most important ones. Considering that the hearing system is part of the neural system, this paper investigates the likelihood of tinnitus occurrence and its potential role of risk factor in patients with type 2 diabetes mellitus (T2DM).

Methodology: This study was conducted on 250 patients from the diabetes center of Birjand, Iran. Data from all patients were collected in 2018, using a demographic questionnaire together with a standard questionnaire.

Results: Sixty six of the 250 patients in the sample set had tinnitus (26\% likelihood of tinnitus occurrence), with 53\% of all subjects having minor disorder. A meaningful dependency between patient's age and severity of tinnitus ( $p<0.05$ ) was found, with tinnitus-related problems becoming more severe among older patients. Also, a meaningful dependency was identified between the duration of diabetes and tinnitus, with the hearing disorder being more severe among patients who had diabetes for more than ten years. No meaningful dependency was found between either patient's gender and tinnitus or the level of fasting blood sugar (FBS) and glycated hemoglobin $\left(\mathrm{Hb}_{1 \mathrm{c}}\right)$. The severity of tinnitus was identified.

Conclusion: The present study indicates that there is an association between the age of patients with diabetes and the severity of tinnitus. Also, the duration of diabetes impacts the likelihood of having tinnitus. In patients with diabetes, tinnitus can be considered as an indicator of the development of neuropathy or a level of microangiopathy of the inner ear.
\end{abstract}

Keywords: tinnitus, type 2 diabetes mellitus, hemoglobin $A_{1 c}$, neuropathy.

\section{INTRODUCTION}

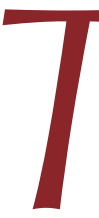

Thnitus is one of the problems related to the hearing system which degrades the quality of life. Tinnitus refers to abnormal hearing sounds in one or both ears in the presence of no external sound source. In one study that was performed in South Korea, this problem is reported in $43 \%$ of diabetes mellitus (DM) patients. Tinnitus may appear without any clear reason, but it is more likely to occur together with either some other problems at the level of the ear or some systematic diseases

\footnotetext{
Address for correspondence:

Batoolsadat Sajadinejad, Ass. Prof. of Otorhinolaryngology, Head and Neck Surgery

Department of Otorhinolaryngology, Birjand University of Medical Sciences, Birjand, Iran

Tel: +98-915-164-0554
} 
such as DM and high blood pressure. Despite the fact that tinnitus, especially its chronic type, is not considered a disease, it creates discomfort in patients by degrading their quality of life due to disruption in concentration or sleep (1). The neurological side effects of DM may lead to dysfunction of the hearing system. The study performed by Sasso et al shows that, in comparison with normal population, DM patients have lower amplitudes of otoacoustic emissions and this impairment is related to the duration of type $2 \mathrm{DM}$ (T2DM) (2). In addition, the study of Prateek Roy et al shows that DM involves vestibular and cochlear functions (3). The existence of diabetes-related hearing loss increases the possibility of diabetic vestibulopathy. It seems that diabetic patients also have impaired vestibular input because the microcirculation that maintains cochlear function is involved with the circulation of the vestibular organs (3).

Diabetes mellitus refers to a group of metabolic diseases that can be identified by either the hyperglycemia resulting from defects in insulin secretion or insulin action, or both factors (4). Vascular complications are the major cause of morbidity and mortality in diabetic patients. These result from interactions between systemic metabolic abnormalities, including hyperglycemia, dyslipidemia, genetic and epigenetic modulators, and local tissue responses to toxic metabolites (5). The long-term symptoms of DM include retinopathy, nephropathy, neuropathy, sexual and heart dysfunction (6). Among different types of DM, T2DM is also referred to as independent diabetes to insulin and it accounts for $90-95 \%$ of worldwide DM cases. During the last three decades, the global population of DM patients doubled, which showed that this disease was one of the most challenging issues for all healthcare systems (7). The risk factors of DM include age, overweight, low physical exercises, pregnancy diabetes background, and family background (8). Measurements of $\mathrm{A}_{1 \mathrm{c}}$ or $\mathrm{HbA}_{1 c}$ levels for DM diagnosis and control have been considered as they reflect the average glucose level during the last two to three months in patient's blood which is directly associated to diabetes symptoms related to narrow and, to some extent, wide blood vessels (9). The level of $\mathrm{HbA}_{1 \mathrm{c}}$ has been shown to be an important test in guiding the care of DM patients. Because of this, $\mathrm{HbA}_{1 \mathrm{c}}$ level has been introduced as a relevant quality measure for both physicians and health care systems (10). One of the most important symptoms of DM is its impact on the neural system by increasing apoptosis through oxidative destruction $(11,12)$. Hyperglycemia can damage neuronal cells by impairing vasodilation and increasing capillary basement membrane thickening and endothelial hyperplasia, which diminishes oxygen tension additionally; also, hyperglycemia reduces $\mathrm{Na}^{+} \mathrm{K}^{+}$ATPase activity, which is essential for maintaining normal nerve resting membrane potential as well as providing neurotrophic support (5).

The present study was motivated by the fact that, despite the impact of tinnitus on the quality of life, only few studies have investigated the association between tinnitus and DM, with DM being a common disease in the Iranian city of Birjand

\section{RESEARCH METHODOLOGY}

This study has been conducted on 250 diagnosed DM patients in Birjand diabetes center over a period of time in 2018. The samples have been taken in a deterministic manner, considering the $30 \%$ tinnitus rate in the general population (1). The number of samples are computed following the equation $n=\left[z^{2} p(1-p)\right] / d^{2}$, where $n$ is the number of samples, $z$ is the standard level according to the normal distribution which is equal to $1.96, p$ is the ratio of the estimated population which contains the desired property, that in our case is equal to 0.3 , and $d$ is the error level that the researcher can neglect, which is considered to be 0.06 in our study. According to the equation, we have $n \approx 250$, and considering the reduction due to partially filled in surveys 250 samples picked. After acquiring the ethical code (Ir.bums.rec.1395.276) and collecting participants' written agreement, the background information about all subjects was collected. In the surveys, answers to two sets of questions, one about age, gender, address, level of education, and another one regarding the background of the sickness, including disease duration, family background of the disease, recorded diagnosis, blood glucose and blood pressure measurements, and treatments were collected from the subjects' medical records. The second part of the survey considered information about the status of each patient's tinnitus, with questionnaire (Tinnitus Handicap Inventory) being certified in two studies $(13,14)$. This questionnaire is com- 
posed of 26 questions about the tinnitus status. First, patients were asked to score each question with a three-level score (Yes: four scores; Occasionally: two scores; and No: 0 scores). Next, the summation of scores was marked as the patient's score. The severity of tinnitus based on acquired scores is ranked into five groups: slight, mild, moderate, severe, and catastrophe. The scores that could be acquired from the inquiry were in the range of 0 to 100 . Patients with a score in the range of 0 to 16 were classified in the slight group, those with scores between 18 and 36 in the mild group, the ones with scores of 38 to 56 in the moderate group, patients with scores of 58 to 76 in the severe group, and those with scores of 78 to 100 in the catastrophic group. In order to be included in the study, patients needed to meet some criteria, including willingness to participate in research, minimum age of 20 years, and ability to understand and speak Persian language. Exclusion criteria included consuming ototoxic medicines in the past, background of neurological disorders, identified inner or outer ear disease, acoustic trauma, head trauma, and analyzed using SPSS 16 software by Chi-square test and independent T-test with parameter 0.05.

\section{RESULTS}

The present study included 250 DM patients, of which $158(63.2 \%)$ were females and $92(36.8 \%)$ males. Sixty six (26.4\%) of all patients - $47(71.2 \%)$ females and $19(28.8 \%)$ males had tinnitus, of which 35 (53\%) patients had a mild degree.

According to the statistics presented in Table 1, the $p$-value of the Chi-square test shows that there is a statistical dependency between age and tinnitus. As age increases, more patients with mild tinnitus are identified.

According to Table 2, it can be concluded that there is no dependency between gender and severeness of tinnitus.

Table 3 shows a dependency between the duration of DM and tinnitus severity, as complaint about moderate and severe tinnitus in patients with DM of less than 10 years duration is more likely.

\begin{tabular}{|l|l|l|l|l|l|l|l|}
\hline \multirow{2}{*}{ Tinnitus severity } & $\begin{array}{l}\text { Slight } \\
\text { count } \\
(\%)\end{array}$ & $\begin{array}{l}\text { Mild } \\
\text { count (\%) }\end{array}$ & $\begin{array}{l}\text { Moderate } \\
\text { count (\%) }\end{array}$ & $\begin{array}{l}\text { Severe } \\
\text { count (\%) }\end{array}$ & $\begin{array}{l}\text { Catastrophic } \\
\text { count (\%) }\end{array}$ & $\begin{array}{l}\text { Total } \\
\text { count (\%) }\end{array}$ & P-value \\
\hline$<50$ & 0 & $2(40)$ & $0(0)$ & $3(60)$ & $0(0)$ & $5(100)$ & 0.01 \\
\hline $50<,<60$ & 0 & $15(44.1)$ & $12(35.3)$ & $7(20.6)$ & $0(0)$ & $34(100)$ & \\
\cline { 1 - 5 } & 0 & $18(66.7)$ & $4(14.8)$ & $2(7.4)$ & $3(11.1)$ & $27(100)$ & \\
\hline Total & 0 & $35(53)$ & $16(24.2)$ & $12(18.2)$ & $3(4.5)$ & $66(100)$ & \\
\hline
\end{tabular}

TABLE 1.

Tinnitus distribution for different age groups

chronic otitis media. Finally, collected data were

\begin{tabular}{|c|c|c|c|c|c|c|c|}
\hline Gender & $\begin{array}{l}\text { Slight } \\
\text { count (\%) }\end{array}$ & $\begin{array}{l}\text { Mild } \\
\text { count (\%) }\end{array}$ & $\begin{array}{l}\text { Moderate } \\
\text { count (\%) }\end{array}$ & $\begin{array}{l}\text { Severe } \\
\text { count (\%) }\end{array}$ & $\begin{array}{l}\text { Catastrophic } \\
\text { count }(\%)\end{array}$ & $\begin{array}{l}\text { Total } \\
\text { count (\%) }\end{array}$ & $\chi^{2}$ \\
\hline Female & 0 & $24(51.1)$ & $13(27.7)$ & $8(17)$ & $2(4.3)$ & $47(100)$ & \multirow[t]{3}{*}{0.77} \\
\hline Male & 0 & $11(57.9)$ & $3(15.8)$ & $4(24.1)$ & $1(5.3)$ & $19(100)$ & \\
\hline Total & 0 & $35(53)$ & $16(24.2)$ & $12(18.2)$ & $3(4.5)$ & $66(100)$ & \\
\hline
\end{tabular}

TABLE 2

Tinnitus distribution by gender

\begin{tabular}{|l|l|l|l|l|l|l|l|l|}
\hline \multicolumn{1}{|c|}{$\begin{array}{c}\text { Tinnitus } \\
\text { severity } \\
\text { Duration } \\
\text { of diabetes }\end{array}$} & $\begin{array}{l}\text { Slight } \\
\text { count } \\
(\%)\end{array}$ & $\begin{array}{l}\text { Mild } \\
\text { count } \\
(\%)\end{array}$ & $\begin{array}{l}\text { Moderate } \\
\text { count (\%) }\end{array}$ & $\begin{array}{l}\text { Severe } \\
\text { count } \\
(\%)\end{array}$ & $\begin{array}{l}\text { Catastrophic } \\
\text { count (\%) }\end{array}$ & $\begin{array}{l}\text { Total } \\
\text { count (\%) }\end{array}$ & $\chi^{2}$ & P-value \\
\cline { 1 - 6 } Shorter than 10 years & 0 & $14(38.9)$ & $10(27.8)$ & $10(27.8)$ & $2(5.6)$ & $36(100)$ & 0.77 & 0.04 \\
\hline Longer than 11 years & 0 & $21(70)$ & $6(20)$ & $2(6.7)$ & $1(3.3)$ & $30(100)$ & \\
\hline Total & 0 & $35(53)$ & $16(24.2)$ & $12(18.2)$ & $3(4.5)$ & $66(100)$ & \\
\hline
\end{tabular}

TABLE 3.

Tinnitus distribution for different duration of diabetes diagnosis 
TABLE 4. Mean and standard deviation of the latest level of fasting blood sugar (FBS) and glycated hemoglobin ( $\left.\mathrm{HbA}_{1} \mathrm{c}\right)$ for different tinnitus status

\begin{tabular}{|l|l|l|l|l|l|l|l|}
\hline $\begin{array}{c}\text { Tinnitus severity } \\
\text { Serum level }\end{array}$ & Slight & Mild & Moderate & Severe & Catastrophic & $\chi^{2}$ & P-value \\
\hline FBS (mg/dL) & - & $152.6 \pm 43.82$ & $159.62 \pm 36.97$ & $188 \pm 75.44$ & $155.53 \pm 43.64$ & 1.67 & 0.64 \\
\hline $\mathrm{HbA} A_{1 \mathrm{C}}(\mathrm{mmole} / \mathrm{mole})$ & - & $8.22 \pm 1.48$ & $8.07 \pm 0.74$ & $8.37 \pm 1.81$ & $7.43 \pm 2.44$ & 0.84 & 0.85 \\
\hline
\end{tabular}

\begin{tabular}{|l|l|l|l|l|}
\hline Tinnitus severity & $\begin{array}{l}\text { Group without } \\
\text { tinnitus }\end{array}$ & $\begin{array}{l}\text { Group with } \\
\text { tinnitus }\end{array}$ & $\chi^{2}$ & P-value \\
\hline FBS $(\mathrm{mg} / \mathrm{dL})$ & $165.38 \pm 59.94$ & $155.53 \pm 43.64$ & 0.16 & 0.87 \\
\hline $\mathrm{HbA}_{\mathrm{IC}}(\mathrm{mmole} / \mathrm{mole})$ & $8.59 \pm 5$ & $8.17 \pm 1.43$ & 0.16 & 0.88 \\
\hline
\end{tabular}

TABLE 5. Mean and standard deviation of the latest level of FBS and glycated hemoglobin $\left(\mathrm{HbA}_{1 \mathrm{c}}\right)$ for different tinnitus status

To compare the average latest level of FBS and A1C regarding the tinnitus status, Kruskal Wallis test has been used. The test outcome showed that there was no meaningful difference between the latest level of FBS and $A_{1 c}$.

Mann-Whitney test results show that there is no meaningful difference between the latest level of FBS and $\mathrm{HbA}_{1 \mathrm{c}}$ in both groups with tinnitus and without tinnitus.

\section{DISCUSSIONS}

In the literature, $19-65 \%$ of patients with DM have been reported to suffer from tinnitus $(13,15)$. In our study on 250 participants, 66 of all subjects had tinnitus; thus, the likelihood of tinnitus in our study group with DM was $26.4 \%$. The majority of patients with tinnitus had mild symptoms. This difference may be due to either the selected statistical population and or regional factors. This study shows that there is a meaningful dependency between patients' age and severity of tinnitus. For subjects with mild tinnitus symptoms, the probability of suffering from tinnitus increases with age. This dependency id also observed among patients with catastrophic tinnitus. However, in the other two groups (patients with moderate and severe tinnitus, respectively), no clear dependency between tinnitus and age were identified, which can be explained by the very low number of patients with tinnitus relatively to the number of those without tinnitus. Among subjects with tinnitus, 92.4\% were over 51 years old. This data is consistent with the study of Kim, that shows a dependency between age and tinnitus severity (16). The reason that tinnitus severity in both groups with moderate and severe tinnitus and age does not have a meaningful dependency can be related to the few number of samples; however, in both groups with mild and catastrophic tinnitus there is an association between age and tinnitus severity, as the percentage of patients with tinnitus in each category increases with age.

The results of the present study show that there is a meaningful dependency between DM duration and tinnitus severity; also, in the group of patients with less than ten years duration of DM, moderate to catastrophic tinnitus has a higher proportion than in the group of subjects with more than ten years duration of DM.

According to Table 3, the number of patients with mild tinnitus increases with DM duration, which implies that most patients with mild tinnitus have more than ten years of DM duration. This is not observed in other groups of patients, which can be due to the low number of subjects with moderate and severe tinnitus. As DM develops, the probability of suffering from neuropathy and degraded hearing due to neuro sensor impairments increases with age, which would impact the study outcome. Increase of DM duration with age and some other symptoms makes interpretations of results more challenging. Therefore, an obvious dependency between tinnitus and DM in patients aged over 60 has not been confirmed (17).

Dependency between age and tinnitus can be due to the duration of DM, as the longer the DM duration, the more severe the side effects of the disease. Somogy et al (18) showed an association between tinnitus and diabetes, with people suffering from DM being more likely to have tinnitus than healthy people of the same age.

There is no meaningful dependency between the levels of $\mathrm{FBS}$ and $\mathrm{HbA}_{1 \mathrm{c}}$ and tinnitus, and the mean and standard deviation of $\mathrm{FBS}$ and $\mathrm{HbA}_{1 \mathrm{c}}$ 
levels was similar in both groups. Also, there is no meaningful dependency between FBS and $\mathrm{HbA}_{1 c}$ levels and tinnitus severity. Therefore, it can be concluded that tinnitus and its severity cannot be predicted based on the levels of FBS and $\mathrm{HbA}_{1 \mathrm{c}}$.

There have been some study limitations that would need to be considered in future follow up research. Considering peripheral neuropathy symptoms of the same cases could have given further insight for the interpretation of findings. Further investigations can address the following research questions: (1) Can tinnitus in diabetes patients be considered as an indication of early stages of diabetes neuropathy and microangiopathy in the inner ear?; and (2) Can the required treatments be considered in the treatment planning to control the side effects of neuropathy and tinnitus developments?

\section{CONCLUSION}

The present study shows a dependency between tinnitus severity and patients' age. Also, it shows that there is no meaningful dependency between the levels of FBS and $\mathrm{HbA}_{1 \mathrm{c}}$ and tinnitus and its severity. This study suggests that patients with a duration of diabetes of less than ten years should be diagnosed for possible tinnitus and its potential side effects.

Conflicts of interests: none declared.

Financial support: none declared.

Acknowledgments: The authors would like to thank the vice dean of research at Birjand Medical University, Iran, and faculty members who have helped us during our research. This paper has been based on the thesis work of a medical student, Sina Khorsandi MD. The authors wish to thank Dr. Hamed Farhadi for his invaluable assistance in editing this manuscript as well as Alie Behroozifar and Dr. Afagh Zarei for assistance in further editing of the paper.

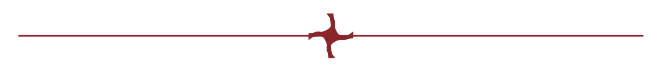

\section{R}

1. Bauer CA. Tinnitus and Hyperacusis. In: Flint PW, Haughey BH, Lund VJ, Niparko JK, Robbins KT, Thomas JR, et al, editors. Cummings otolaryngology-head and neck surgery. $5^{\text {th }}$ ed, Philadelphia: PA Mosby/Elsevier, 2015, p 2336.

2. Sasso FC, Salvatore T, Tranchino G, et al. Cochlear dysfunction in type 2 diabetes: A complication independent of neuropathy and acute hyperglycemia. Metabolism 1999:48:1346-1350.

3. Roy $\mathbf{P}$, Chandra M, Mishra A, et al. Otological and Visual Implications of Diabetes Mellitus in North Indian Population.

Indian J Otolaryngol Head Neck Surg 2019;71(S2):1639-1651.

4. Ginter E, Simko V. Type 2 Diabetes Mellitus, Pandemic in 21st Century. In: Advances in Experimental Medicine and Biology [Internet], Springer, 2013, pp 42-50.

5. Barrett EJ, Liu Z, Khamaisi M, et al. Diabetic Microvascular Disease: An Endocrine Society Scientific Statement. J Clin Endocrinol Metab 2017;102:4343-4410.

6. Zinman B, Wanner C, Lachin JM, et al. Empagliflozin, Cardiovascular Outcomes, and Mortality in Type 2 Diabetes. N Engl J Med 2015;373:2117-2128.

7. Chen L, Magliano DJ, Zimmet PZ. The worldwide epidemiology of type 2 diabetes mellitus - present and future perspectives.

Nat Rev Endocrinol 2012;8:228-236.

8. Yau JWY, Rogers SL, Kawasaki R, et al. Global Prevalence and Major Risk Factors of Diabetic Retinopathy. Diabetes Care 2012;35:556-564.

9. Braga F, Dolci A, Mosca A, Panteghini M. Biological variability of glycated hemoglobin. Clin Chim Acta 2010;411:1606-1610.

10. Goodney PP, Newhall KA, Bekelis K, et al. Consistency of Hemoglobin A1c Testing and Cardiovascular Outcomes in Medicare Patients With Diabetes. J Am Heart Assoc 2016;5:1-12.

11. Prolla TA, Mattson MP. Molecular mechanisms of brain aging and neurodegenerative disorders: lessons from dietary restriction.

Trends Neurosci 2001;24:S21-S31.

12. Mattson M. Suppression of brain aging and neurodegenerative disorders by dietary restriction and environmental enrichment: molecular mechanisms. Mech Ageing Dev 2001;122:757-778.

13. Jalali MM, Soleimani $R$, Fallahi $M$, et al. Psychometric Properties of the Persian Version of the Tinnitus Handicap Inventory (THI-P). Iran J Otorhinolaryngol 2015;27:83-94.

14. Newman CW, Jacobson GP, Spitzer JB. Development of the Tinnitus Handicap Inventory.

Arch Otolaryngol Head Neck Surg 1996;122:143-148.

15. Pandey D, Pandit A, Pandey AK. Study of audio vestibular dysfunction in type 2 diabetes mellitus. Int Arch Integr Med 2016;3:23-26.

16. Kim H-J, Lee H-J, An S-Y, et al. Analysis of the Prevalence and Associated Risk Factors of Tinnitus in Adults. Chen L, editor. PLoS One 2015;10:e0127578.

17. Baiduc RR, Helzner EP. Epidemiology of Diabetes and Hearing Loss. Semin Hear 2019;40:281-291.

18. Somogyi A, Rosta K, Vaszi T. Hearing impairment and tinnitus in patients with type 2 diabetes. Orv Hetil 2013;154:363-368. 